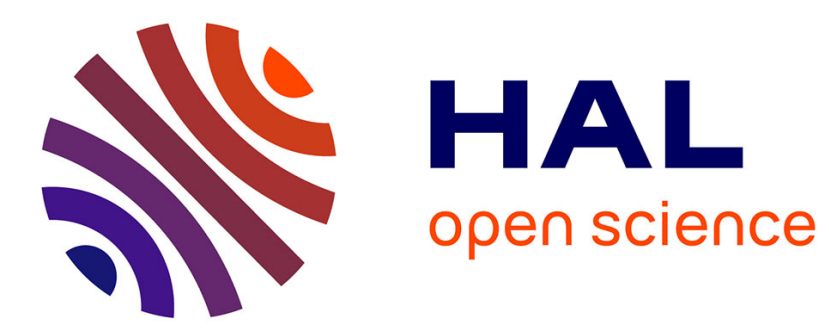

\title{
STRUCTURAL DESCRIPTION OF TRANSITION METAL-METALLOID GLASSES
}

\author{
Jessica Dubois, Gérard Le Caër
}

\section{To cite this version:}

Jessica Dubois, Gérard Le Caër. STRUCTURAL DESCRIPTION OF TRANSITION METALMETALLOID GLASSES. Journal de Physique Colloques, 1982, 43 (C9), pp.C9-67-C9-74. 10.1051/jphyscol:1982912 . jpa-00222425

\section{HAL Id: jpa-00222425 https://hal.science/jpa-00222425}

Submitted on 1 Jan 1982

HAL is a multi-disciplinary open access archive for the deposit and dissemination of scientific research documents, whether they are published or not. The documents may come from teaching and research institutions in France or abroad, or from public or private research centers.
L'archive ouverte pluridisciplinaire HAL, est destinée au dépôt et à la diffusion de documents scientifiques de niveau recherche, publiés ou non, émanant des établissements d'enseignement et de recherche français ou étrangers, des laboratoires publics ou privés. 


\title{
STRUCTURAL DESCRIPTION OF TRANSITION METAL-METALLOID GLASSES
}

\author{
J.M. Dubois and G. Le Caer \\ Laboratoire de Métallurgie (L.A. 159) ENSMIM, Parc de Saurupt, \\ 54042 Nancy Cedex, France
}

\begin{abstract}
Résumé - On propose une description structurale des verres métal de transition-métal1ợde qui s'appuie sur les opérations structurales qui permettent de générer les composés cristallins. Une démixtion à 1 'échelle microscopique s'introduit naturellement et ses conséquences sur la structure sont discutées. On apporte des arguments expérimentaux en faveur d'une telle description qui pourrait fournir un moyen de prévoir certaines propriêtés des verres métalliques.

Abstract - A structural description of transition metal-metalloid glasses is proposed. It is based on the structural operations which allow generating the crystalline counterparts. A demixion at a microscopic level is naturally introduced whose conséquences on the structure are discussed. Experimental arguments in favour of such a description are given which should provide a basis for the prevision of some properties of metallic glasses.
\end{abstract}

\section{Introduction}

The notion of stereochemically defined amorphous structures has recently emerged from the field of models devoted to the structural description of metallic glasses (1). As emphasized by GASKELI (1), numerous experimental evidences demonstrate that one atomic species is embedded ina definite polyhedron formed from the other species. For energetical reasons, this cluster may be the most stable of all the possible configurations and thus be the basic structural unit of both the glassy and crystalline states.

Metallic glasses formed from transition metals $\mathrm{M}$ (Mn, $\mathrm{Fe}$, Co, $\mathrm{Ni}$, Pd) and from metalloids $X(B, C, P, S i)$ have been extensively studied in recent years. Many structures of M-X crystalline compounds can be built with the help of metallic trigonal prisms centered by the metalloid atom. Only the way they are interconnected is to be changed to account for the different structures. Therefore, the trigonal prism seens to be the best candidate as a basic structural unit of this type of metallic glasses. GASKELL (2) indeed succeeded by using it in a structural model of a $-\mathrm{Pd}_{80^{-}} \mathrm{Si}_{20}$.

The purpose of this paper is thus to extent the "hand building" algorithm of this model (2) by proposing a general description of the arrangements of trigonal prisms which should be suited for all $\mathrm{M}_{1-\mathrm{x}_{\mathrm{x}}} \mathrm{x}$ glasses $(0.1 \leqslant \mathrm{x} \leqslant 0.3)$. After justifying the choice of this polyedron as $1-x \times$ a structural $\sim$ unit on the basis of experimental data, we will describe the structures of the $M-X$ compounds in terms of chemically twinned close packed structures. From this systematics, a description of the amorphous structure will be given leading to the definition of two noteworthy compositions. Experimental chess of their existence will then be reported. Finally, as a matter of conclusion, a prospective account of some characteristic features of this description will be given.

\section{Physical properties of $M_{1-x} x_{x}$ glasses and crystalline compounds}

Numerous experimental studies have demonstrated that the local properties measured in $M-X$ glasses are quite similar to those of the crystalline cointerparts. The most informative data were obtained from techniques using the $X$ element as a local probe. PANISSOD et a1. (3) have shown by NMR that the quadrupole splittings at ${ }_{1} \mathrm{~B}$ nuclei in Mo7.0 $\mathrm{B}_{30}$ and $\mathrm{Ni}{ }_{8} \mathrm{P}_{14} \mathrm{~B}_{8}$ glasses are nearly identical to those measured in $\mathrm{Mo}_{3} \mathrm{~B}$ and $\mathrm{Ni}_{3} \mathrm{~B}$ respectively. The average hyperfine field transfered from the iron neighbours to boron in a $-\mathrm{Fe}_{82} \mathrm{~B}_{18}$ is identical to the transfered field measured in 
c - $\mathrm{Fe}_{3} \mathrm{~B} \varepsilon_{1}(4)$. These results allow assuming the metal polyedron surrounding the metalloid is similar in both structures. Taking the iron atom as a local probe, the Mössbauer spectroscopy has evidenced a lot of similarities in iron based glasses and crystalline compounds. For example, the hyperfine field distribution calculated from the spectrum a of $a-\mathrm{Fe}_{75} \mathrm{~B}_{25}(\mathrm{~T}=4 \mathrm{~K})$ argues in favour of similar metalloid distributions around the metal atom in the two glassy and crystalline states (figure 1). In fact, not only this distribution at given concentration but also its evolution with the metal content is similar in both states. Conclusive results seem to be indeed provided by the non random substitution of iron in $\mathrm{Co}_{1}{ }^{B}$ glasses as it occurs in the $\mathrm{CO}_{3} \mathrm{~B}$ boride (5) and by the evolution of the hyperf $\mathrm{x}$. $\left(F e_{1-2} \mathrm{Ni}_{z}\right)-\mathrm{B}$ glasses. Which exhibit the changes at $z=0.4$ characteristic of the tetragonal to orthohombic transition of the $\left(\mathrm{Fe}_{1-2} \mathrm{Ni}_{2}\right)_{3} \mathrm{~B}$ borides (6).

Strong similarities of the d bands are observed by XPS in glassy alloys and their crystalline counterparts while the crystalline pure metal d band is different (7). Finally, some other physical properties are closely related in bulk amorphous and crystalline materials. This is the case in the Fe $79(P, B) 21$ glasses and $F F_{3}(P, B)$ phosphoborides which exibit the same slope change of the $T_{C}$-composition relation at $z=P / B=0.5(8)$. The glasses are less dense than the ${ }^{c}$ crystalline compounds by only few percents. Moreover, the packing fraction $n$ of the metal atoms varies with the radii ratio $p=r_{x} / x_{M}$ in close similarity with the change of $n$ in $M_{3} X$ compounds (9).

Thus, indirect methods of probing the local order leads us to conclude that, at a very fine scale, the glassy structure is formed from the same units as the crystalline compounds. A similar conclusion can be drawn from the direct study of the structure by diffraction methods. The first conclusive remark is that the $X$ atoms are isolated from other $X$ atoms by a $M$ shell as shown by neutron diffraction in in a lot of $M-X$ glasses. Secondly, the mean number of $M$ first neighbours of the $X$ element is found to be $\overline{\bar{Z}} \simeq 9$ by different techniques (table 1 ). This value of $\bar{z}$, which is also obtained by Mössbauer spectroscopy in $\mathrm{Fe}_{1-\mathrm{x}} \mathrm{B}_{\mathrm{x}}$ glasses $\overline{(\bar{z}}=9+1.5$ for $x \geq 0.2(15))$ is exactly equal to the $1-x$ coordination number of metailoid in the $\mathbb{M}_{3} \mathrm{X}$ compounds.

\begin{tabular}{|c|c|c|c|}
\hline Composition & $\bar{z}$ & Me thod & Referencs \\
\hline $\mathrm{Fe}_{80} \mathrm{~B}_{20}$ & 8.64 & R.X. and neutron dif. & (10) \\
\hline $\mathrm{Fe}_{75} \mathrm{P}_{25}$ & 8.1 & R.X. dif. & (11) \\
\hline $\mathrm{CO}_{81} \mathrm{P}_{19}$ & $8.9 \pm 0.5$ & R.X.and neutron dif. & (12) \\
\hline $\mathrm{Pd}_{84} \mathrm{Si}_{16}$ & $9.0 \pm 0.9$ & $"$ & (13) \\
\hline $\mathrm{Pd}_{78} \mathrm{Ge}_{22}$ & $8.6 \pm 0.5$ & EXAFS & (14) \\
\hline
\end{tabular}

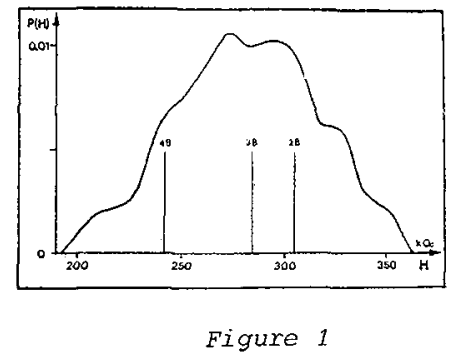

TABLE 1

Hyperfine fie $\overline{l d}$ distribution of a $\mathrm{Fe}_{75} \mathrm{~B}_{2}$ sand hyperfine fields in $\mathrm{Fe}_{3} \mathrm{BE},(T=4 \mathrm{~K})$

Moreover, the distortion of the metallic shell around the metalloid resembles that encountered in $\mathrm{M}_{3} \mathrm{X}$ compounds : distorded in a-Pd ${ }_{4} \mathrm{Si}_{16}$ as in $\mathrm{Pd}_{3} \mathrm{Si}$ (1), sharply deftned in $\mathrm{a}-\mathrm{Fe}_{80} \mathrm{~B}_{20}(10)$ as in $\mathrm{Fe}_{3} \mathrm{~B} \varepsilon_{1}(16)$. Finally, $\mathrm{M}-\mathrm{M}$ and $\mathrm{M}-2 \mathrm{nn} \mathrm{X}$ distances in the amorphous state are also compatible with the $2 \mathrm{nn}$ distances in $M_{3} X$ compound ( 1 ) The best suited structural unit for liquid quenched
(i.e. $x \leqslant 0.3$ ) is the so-called tetrakaidecahedron centered on the ${ }^{M} 1-x^{X} x$ glasses
metalloid and formed from a trigonal prism with six metal atoms at each vertex and three further metals capping the rectangular faces. This interstitial site optimizes the packing efficiency of the metallic atoms and the space needed by the metalloid atom. Finally, it may be reasonably assumed that the correlations between units in the crystalline countexpart remain similar in the glass. Therefore, a description of the amorphous structure grounded on the crystalline short range order and which avoids the settling of a long range order should be adapted to $M_{1-x} X_{X}$ glasses. 


\section{The $M-X$ compounds as chemically twinned CP structures}

HYDE, ANDERSON and coworkers (17) have shown that the apparently complex structures of the $\mathrm{M}-\mathrm{X}$ compounds can be simply generated from :close packed structures (hcp of $\mathrm{fcc}$ ) by periodically twinning these structures on the unit cell level. The prismatic interstices are created in the twinning plane called the composition plane. The periodicity and the twin plane type (hereafter termed the structural operation) depend on the actual structure and are labelled in reference (17) as chemical twinning, triling, fourling, swinging twinning, etc. For the sake of brevity, we only describe the generation of the $\mathrm{Fe}_{3} \mathrm{C}$ and $\mathrm{Fe}_{5} \mathrm{C}_{2}$ type structures by chemical twinning (18).

The composition plane is the $(11 \overline{2} 2)$ plane of the hep structure and the twinning is repeated every four $\mathrm{plane}$ in $\mathrm{Fe}_{3} \mathrm{C}$ or in the $\{3,4,3,4 \ldots\}$ sequence in $\mathrm{Fe}_{5} \mathrm{C}_{2}$ (figure 2). Between two twinning planes, the $M$ atoms remain very close to the original hep positions thus forming almost perfect hep blocks. In $\mathrm{Fe}_{3} \mathrm{C}$ type structures, every second block is rotated $180^{\circ}$ around the twing axis and joined exactly to the adjacent blocks accross the twin planes. Two adjacent prisms share a trigonal edge forming chains of trigonal prisms. The chains are connected in the twinning plane by sharing vertices of trigonal prisms.

It is obviously the nature of the structural operation and its periodicity, that means the connectivity rules between structural units, which accounts for the stoichiometry without introducing point defects. PARTHE and MOREAU (19) have defined a linkage coefficient LC which represents the number of prisms to which a metal atom belongs. On the average, $\overline{\mathrm{LC}}=6 \mathrm{x} /(1-\mathrm{x})$ varies between 1 and 12 if all metal atoms belong to trigonal prisms. The former value corresponds to isolated prisms while for the latter the space is tiled only with prisms. Finally, when $\overline{\mathrm{LC}}<1$, some of the
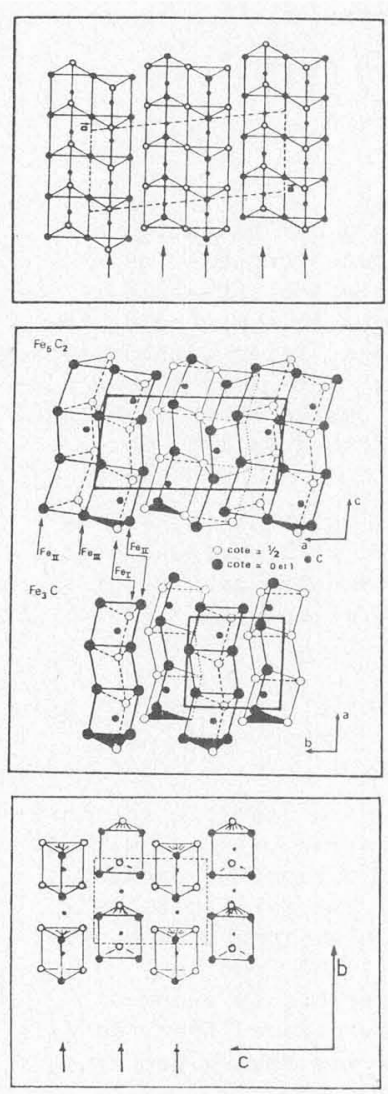
metal atoms do not belong to any prism. The $0 \leq \overline{\mathrm{LC}} \leq 12$ range allows thus scanning the $0 \leq x \leq 0.67$ composition range.

\section{Structural description of $M_{1-x} X_{x}$ glasses}

We propose to generate the glass like the crystalline compound of same composition with the help of the same structural operation, i.e. chemical twinning in $\mathrm{Pd}_{75} \mathrm{~S}_{\mathbf{i}_{2}}$, $\mathrm{Co}_{75} \mathrm{~B}_{25}$, chemical fourling in $\mathrm{Fe}_{75} \mathrm{~B}_{25}$, etc. The lack of long range periodicity can simply arise from the limited spatial extent of the structural operation. Above a given coherent length 1 , the composition plane is randomly changed for an other plane crystallographically equivalent. For example, in $\mathrm{Pd}_{3} \mathrm{Si}$ there are three equivalent (11 2 2) planes which can be randomly chosen as composition planes. Both the units and chains connections are thus defined by the structural operation.

The metalloid content is simply accounted for by changing the connectivity between the prismatic units, that means by varying the periodicity and/or the structural operation. This allows for example keeping constant the number $\mathrm{n}_{\mathrm{x}}$ of metalloid nearest neighbours of a metal atom when $x$ decreases, because a metal atom may belong to LC prisms and caps the rectangular faces of $\left(n_{x}-L C\right)$ other prisms. This feature accounts for the striking independen$c y$ on $x$ of the standard deviation of the hyperfine field distributions in Fe-B glasses (15).

\section{Figure 2}

Schematic drawing of the structure of $\mathrm{Fe}_{3} \mathrm{C}$ and $\mathrm{Fe}_{5} \mathrm{C}_{2}$ (centex) and projections on the (100) plane of the Fe, ${ }^{C}$ structure (below) and on the (O10) plane of the $\mathrm{Fe}_{5} \mathrm{C}_{2}$ structure (above). The traces of the twinning planes are marked by arrows (after (18)). 
The formation of microcrystals is forbidden on one hand by the magnitude of 1 which is assumed to be of the order of the lattice parameters of the M-X compounds and on the other hand by the fact that two adjacent domains can be joined together by a hcp plane with only slight distorsions. This leads of course to the formation of linear defects closing the composition. planes whose length is crudely approximated by $\pi 1_{a}$. We identify 1 with the cross dimension of the interference fringes patterns observed by high resolution electron microscopy in a-Pd ${ }_{0} \mathrm{Si}_{20}(20)$, i.e. $1_{a} \simeq 15 \AA$. This value is in agreement with the extent of local defects shown by ${ }^{a}$ NOLD et al. in a - Feso $B_{20}(21)$

As already emphasized, there is a metalloid concentration $x_{1}$ below which metal atoms do not belong to structural units, namely :

$$
\mathrm{x}_{1}=\frac{\overline{\mathrm{n}}_{\mathrm{X}}}{\mathrm{Z}+\overline{\mathrm{n}}_{\mathrm{x}}}
$$

where $Z$ is the number of faces of the Voronot polyedron of $X$ and $\bar{n}$ the average number of $M-X$ pairs. In the $c$ ase of tetrakaidekahedra, this concentration limit is at least $x_{1}=1 / 10$ but may be higher if metal atom tend to be surrounded by more than one $\mathrm{X}$ neighbour.

Below this concentration limit $x_{1}$, a demixion occurs at a very fine scale $(\simeq 1$ ) and the structure may be described as being formed from two kinds of metallic environments :

1 - Metal atoms which belong to tetrakaidekaedra with an average number of $X$ neighbours $\bar{n}_{x} \geq 1$. The mean composition of this region is thus $M_{1-x_{1}} x_{1}$ (hereafter
called $A_{X}$ envixonment).

2 - Dense random packed metal atoms with no metalloid neighbour which fill the space between the $A_{X}$ regions (hereafter called $A_{M}$ environment).

The relative fraction of metal atoms in the $A_{M}$ regions is simply :

$$
\alpha=1-\frac{x}{1-x} \frac{1-x_{1}}{x_{1}}
$$

and is reported on figure 3 for different values of $x_{1}$.

on principle, the metalloid atoms lie in the composition plane as introduced above and therefore it is reasonable to assume that the coherence length 1 on $1 \mathrm{y}$ slightly depends on $x$ when $x \leq x_{1}$. Thus, a connectivity percolation threshold $x$ is associated to the demixion below $x_{1}$. When $x<x_{p}$, this connectivity percolation problem expresses the existence of an infinite walk from $A_{M}$ to $A_{M}$ sites without seeing any $X$ atom as first neighbour. In other words, above $\dot{x}_{p}$ the $A_{X} M$ regions form an infinite cluster containing smal1 A aggregates. The demixed $\mathrm{A}$ glass shows thus concentration fluctuations of wave ${ }^{M}$ length $\lambda$ which can be identified with ${ }^{1}$ for $\mathrm{x}=\mathrm{x}_{\mathrm{p}}$.

Two crude estimates of $x$ can be given. If we consider first that the $A$ regions have an almost spherical ${ }^{\mathrm{P}}$ shape, the percolation threshold will correspond to the composition at which they remain just in contact and form a dense packing of spheres, thus accupying a fraction $\left(1-f_{p}\right)=\pi \sqrt{2} / 6$ of the total volume. $f_{p}$ is related to $x_{p}$ by :

$$
\frac{x_{p}}{1-x_{p}}=\frac{x_{1}}{1-x_{1}}\left[\frac{\left(1-f_{p}\right) \bar{\Omega}_{M}}{\left(1-f_{p}\right) \bar{\Omega}_{M}+f_{p} \bar{\Omega}_{X}}\right]
$$

where $\bar{\Omega}_{\mathrm{J}}$ is the actual mean atomic volume in region $\mathrm{A}_{\mathrm{J}}$. It is also possible to consider only the metallic network and fill the $M$ sites with metal atoms with and without $\mathrm{X}$.atoms as nearest neighbours. By neglecting as a first approximation the packing differences which arise from the actual presence or absence of the metalloid, this percolation problem is quite similar to a site percolation problem in a random network. Solutions are provided from computer simulations $(22,23)$ and lead to $0.21 \leq \alpha \leq 0.26$ if the average coordination number of the network is assumed to be $9 \leq \mathrm{P} Y \leq 12$. This coordination number range is typically deduced from the diffraction measurements in $M-X$ glasses. The second estimate of $x_{p}$ is thus given by : 


$$
\frac{{ }_{p}}{1-x_{p}}=\frac{x_{1}}{1-x_{1}} \quad\left(1-\alpha_{\dot{p}}\right)
$$

Figure 4 pictures this description for the three concentration ranges $x>x_{1}, x_{p}<x<x_{1}$ and $x<x_{p}$. In the latter concentration range, the concentration fluctuation wavelength $\lambda$ increases due to the decrease of the number of $A_{X}$ zones while the average size of these zones remains close to 1 . However, in the usual composition range of the liquid quenched glasses $\left(0.1<{ }^{a} x<0,3\right)$, $\lambda$ cannot significantly differ from $10-20 \AA$. This range clearly distinguishes this demixion phenomenon from the long wavelength fluctuations (1000 $\AA$ ) already published in the $1 i-$ terature.

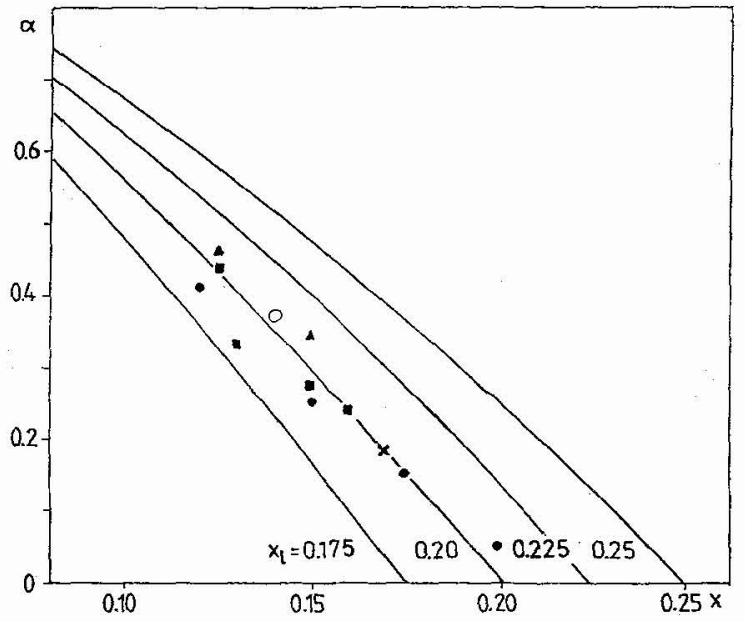

Figure 3

Fraction $\alpha$ of metallic atoms embedded in the $A_{M}$ regions for different values of $x_{7}$. Experimental data in Fe-B glasses from references $(15), \mathbf{1}(24), \mathbf{a}(25)$, o $(26), \mathbf{x}(27)$.

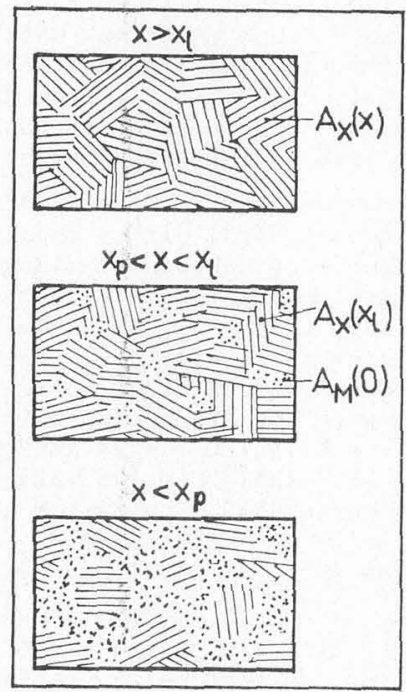

\section{Figure 4}

Picture of the structure for $x>x_{1}, x_{p}<x<x_{I}$ and $x<x_{p}$

\section{Experimental check of the proposed description}

The Fe $B$ glasses exhibit some well known changes in their physical properties-composition relationships. They seem therefore to be good candidates for checking the above description. Especially, they crystallize in multiple steps at low boron content ( $x<0.17$ ) (the first one corresponds to the formation of pure bcc Fe). Assuming that this bcc Fe results from the crystalization of $A_{\text {fe }}$ zones embedded in $A_{B}$ zones of composition $\mathrm{Fe}_{1-{ }^{B}}$, differential enthalpic analysis (24) and resistivity during crystallization $x_{1}$ (25) measurements allow determining the experimental fraction $\alpha$ reported on figure 3. A similar defermination of a in partially crystallized glasses by Mössbauer spectroscopy $(x=0.14)(26)$ and resistivity $(x=0.17)$ (27) is also reported in figure 3. Finally the hyperfine field distributions calculated from the Mössbauer spectra of as-quenched glasses also furnish values of $\alpha$ by comparing the measured value of $\bar{Z}$ to the expected one $\bar{Z}=9$ (15). As a good agreement between $\alpha$ values from as quenched and heat treated glasses is observed, a reliable composition limit can be least square fitted to the data of figure 3 , i.e (for Fe-B glasses): 


$$
x_{1}=0.20 \pm 0.01
$$

which agrees with the change slope of the density.

From eq. 3 and 4 , the percolation threshold is estimated to 1 ie in the range $0.15 \leq x_{p} \leq 0.16$. This concentration range corresponds to the composition of the INVAR $\mathrm{P}$ Fes ${ }_{3} \mathrm{~B}_{17} \mathrm{glass}$ and allows us to suggest that the INVAR behaviour of the glasses is the result of the percolation of two magnetically different regions of the structure. This suggestion is also in agreement with the slope change near $x=0.15$ of the magnetic moment at $4 \mathrm{~K}$ and the description of the hyperfine field distributions given in ref.(15).

The small angle scattering techniques should be sensitive to the demixion. SAXS in $\mathrm{Feg}_{3} \mathrm{~B}_{17}$ (27) in fact gives $\lambda=12 \AA$, in quite satisfactory agreement with our

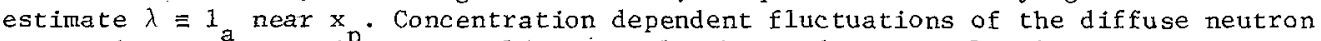
scattering cross sectibns were also recently observed in $F e^{B}$ glasses for $x \leq 0.19$ (28). Finally, the demixion entails specific features $x$ as the lienar variations of the extensive thermodynamical variables when $x<x_{1}$ such as the volume par atom gram or the crystalization enthalpy (24).

Quantitative checks of the structure of boron rich glasses $\left(x>x_{1}\right)$ appear to be more difficult to obtain. However, the obvious agreement between the assumed existence of coherent domains and the observed ones (20) was already mentionned. It is also consistent with the $B-B$ medium range correlations shown by LAMPARTER et al. (29) in a $-\mathrm{Ni}_{8}{ }_{1} \mathrm{~B}_{19}$. The first metastable boride which appears during the crystallization cascade of $\mathrm{a}-\mathrm{Fe}_{75} \mathrm{~B}_{25}$ is $\mathrm{Fe}_{3} \mathrm{~B}_{\varepsilon_{1}}$ while different authors have given some evidence that an other boride forms in $\varepsilon_{1}$ a-Feso $B_{20}$ ( 30 ). This observation is coherent with the assumption that the connectivity between prisms evolves when $\mathrm{x}$ decreases. For $x=0.25, \overline{L C}=2$ as in $F e_{3} B \varepsilon_{1}$ while $\overline{L C}=1.5$ for $x=0.2$. Therefore, a borlde with an actual $\overrightarrow{\mathrm{LC}}=1.5$ value ${ }^{3} \mathrm{my}$ form $\mathrm{first}$. In low boron content glasses $(x<x$ ), long range diffusion of boron is hintered during the second crystallization step ${ }^{p}$ by the bcc Fe zones already formed. The A aggregates gives thus a first metastable boride which is obviously different from $F_{3} B \varepsilon_{1}$ as recently shown by $J$. WELFRINGER (31).

Till now, there is no clear evidence that a demixion prevails in other binary glasses. In particular, the density varies linearly with $\mathrm{x}$ in all the other glasses (9). The slope change of the density in Fe-B glasses seems therefore to be a specific feature of this system. However, it is worth noticing that the other considered glasses are formed form transition metals whose crystalline structure is close-packed unlike bcc Fe. For such glasses, no significant change of the density is to be expected below $x_{1}$ (provided $x_{1}$ is higher than the lower limit of the amorphous composition range) ${ }^{1}$ if the $A_{M}$ structure resembles that of the pure metal. Nevertheless, some properties like transport properties should be sensitive to the existence of a demixion and provide further checks of our description.

Finally, the Fe- $\left(X, X^{\prime}\right)$ glasses are also relevant to this description. For example, the $\mathrm{Fe}_{1-x-\mathrm{y}_{\mathrm{H}} \mathrm{B}}$ glasses $\left(x<\mathrm{x}_{1}\right)$ exhibit drastic changes of all their physical properties for silicon concentrations $y_{1}$ depending of $x$. In the framework of the above description, it is possible to calculate $y_{1}$ by assuming that, due to strong repulsions between metalloid species which avoid ${ }^{1}$ forming $S i-S i, B-B$ and $B-S i$ pairs, silicon enters first the $A_{F e}$ zones substituting for Fe atoms until the $\mathrm{A}_{\mathrm{Fe}}$ order is maximum. Assuming that $\mathrm{x}_{1}$ Foes not depend on the silicon content, $y_{1}{ }^{\text {is }}$ defined by :

$$
\mathrm{y}_{1}=\beta_{1}\left[1-\mathrm{x} / \mathrm{x}_{1}\right]
$$

where $\beta_{1} \simeq 0.29$ corresponds to the maximum chemical order in a random network of composition $M_{1-\beta} X_{B}$ (32). Experimental values of $y_{1}$ taken from the slope changes of density, $\quad 1-3$ microhardness, quadrupole splitting (33) and initial permeability (34) measurements in Fe-Si-B glasses are satisfactorily accounted for by equation $16 /$ as shown in figure 5 (solid line). The agreement is improved by taking $\beta_{1}=0.25$ (dashed line) which suggests that the mean Fe-Fe coordination in the $A_{F e}$ zones is close to 8 as in bcc iron. The packing fraction $\eta_{M} \simeq 0.69$ calculated from the density measurements of HASEGAWA and RANJAN RAY (35) ${ }^{\mathrm{M}}$ a1so supports this assumption. 


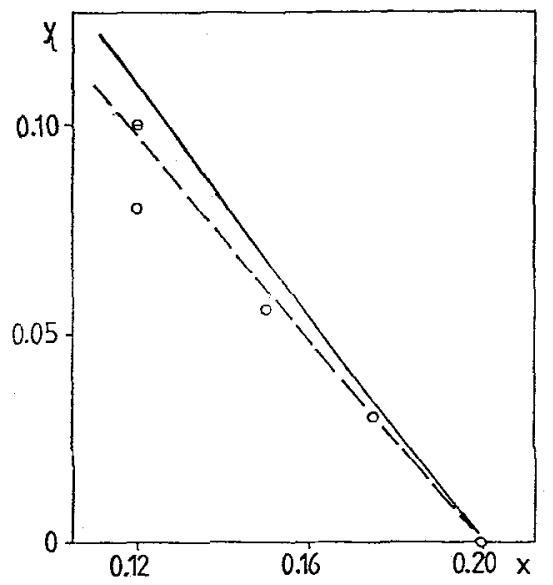

Figure 5

Silicon concentration $\overline{y_{I}}$ in $F e_{1-x-y} S^{B}{ }^{B} x$
glasses. The solid line was calculated with eq $/ 6 /$ by using $\beta_{1}=0.29$ and the dashed Iine by using $\beta_{I}=0.25$ (o from (33), $\theta$ from (34)).

\section{Conclusion and perspectives}

We have proposed a structural description of $\mathrm{M}-\mathrm{X}$ glasses which appears well suited to account for the pecularities of iron based glasses. However, we believe that this description may also provide some understanding of the structure of other stereochemically defined glasses (for instance rare earth-transition metal glasses).

Besides the need of a direct check of this description by computer modelling $\mathrm{M}-\mathrm{X}$ networks for different compositions, it should be interesting to further study the two following aspects. On the one hand, the limited extent of the composition planes introduces linear defects as a natural consequence of the existence of the glassy state. The defect density may be crudely estimated for a $\{4,4,4\}$ twinning sequence as $d \sim n I^{-2}$ where $\mathrm{n} \simeq 5$ is the mean number of twinning planes per coherent domain, leading thus to $\mathrm{d} \simeq 10^{14}-10^{15} \mathrm{~cm} \mathrm{~cm}^{-3}$ * which should be useful in the interpretation of the outstanding mechanical properties of the glasses. In the recent models of SADOC (36), the closing of dense domains by sets of defects and local distorsions are also natural consequences of the mapping a non euclidian space onto the cartesian space.

On the other hand, the description seems to be able to provide a guide for calculating thermodynamical data (24). As the structural operations can take place at the undercooled liquid-glass interface (19), the existence of clusters defining internal surfaces leads the $M-X$ glasses to be also relevant to the kinetic "flaking" model of PHILIPS for the glass transition (37) while it has already been emphasized by this author that the metallic prism well corresponds to his glass forming condition (38). According to him, the maximum glass forming tendency may be expected when the demixion begins and thus creates the best defined internal surfaces which act as barriers against crystallization, i.e. around $x_{p}<x<x_{1}$ as it is indeed observed. Acknowledgements - Enlightening discussions with Dr. P.H. GASKELL are gratefully acknowledged. We thank Dr. J.P. SENATEUR for the central part of figure 2 taken form his thesis (Paris 1967).

\section{BIBLIOGRAPHY}

(1) P.H. GASKELI, Proc. 4 th Int. Conf. R.Q.M. Sendai 1 (1982) 247

(2) P.H. GASKELL, J. Non Cryst. Sol. 32 (1979), 207.

(3) P. PANISSOD, D. ALLIAGA-GERRA, A. AMAMOU, J. DURAND, W.I. JOHNSON, N.I. CARTER, S.J. POON, Phys. Rev. Lett. 44-22 (1980), 1465.

(4) V.S. POKATILOV, Sov. Phys. Dokl. 26 (3), (1981), 327.

(5) J.M. DUBOIS, G. LE CAER, Sol. State Comm. in press.

(6) T. KEMENY, I. VINCZE, J. BALOGH, L. GRANASY, B. FOGARASSY, F. HAJDV, E. SVAB, Int. Conf. Met. Glasses : Science and Technology Budapest (1980).

(7) M. MATSUURA, T. NOMOTO, F. ITOH, K. SUZUKI, Sol. State Comm.

(8) J. DURAND IEEE Trans. Mag. MAG 12 (1976) 945.

(9) P.H. GASKELL, Acta Met. 29 (1981) 1203.

* and not $10^{17}-10^{18} \mathrm{~cm} \mathrm{~cm}^{-3}$ as given in (15). 
(10) E. NOLD, P. LAMPARTER, H. OLBRICH, G. RAINER-HARBACH, S. STEEB, Z. Naturforsch. 36 a (1981) 1032 .

(11) Y. WASEDA, RQM III, Brighton 2 (1978) 352.

(12) J.F. SADOC, J. DIXMLER, Mat. Sc. Eng. 23 (1976) 187.

(13) J.F. SADOC, Thesis Orsay (1976).

(14) T.M. HAYES, J.W. ALIEN, T. TAUC, B.B. GIESSEN, J.J. HAUSER, Phys. Rev.-Lett. $40-9$ (1978) 1282 .

(15) J.M. DUBOIS, G. LE CAER, Nucl. Instr. Methods, in press.

(16) S. RUNDQVIST, Acta Chem. Scand. 16, (1962) 1.

(17) B.G. HYDE, S. ANDERSON, M. BAKKER, C.M. PLUG, M. O'KEEFFE, Prog. SOIid. St. Chem. 12, (1979), 273.

(18) S. ANDERSON, G. B. HYDE, J. Sol. Sttat. Chem. 9 (1974) 92.

(19) E. PARTHE, J.M. MOREAU, J. Less Common Metals 53, (1977) 1

(20) P.H. GASKELL, D.J. SMITH, C.J.D. CATTO, J.R.A. CLEAVER, Nature 281 (1979) 465.

(21) E. NOLD, S. STEEB, P. LAMPARTER, Z. Naturforsch. 35 a (1980) 610.

(22) M.J. POWELI, Phys. Rev. B 21-8 (1980) 3725.

(23) M. AHMADZADEH, A.W. SIMPSON, Phys. Rev. B 25-7 (1982) 4633.

(24) C. CUNAT, M. NOTTIN, J. HERTZ, J.M. DUbOIS, C. LE CAER, J. Non Cryst. Sol. submitted

C. CUNAT, J. HERTZ, J.M. DUBOIS, G. LE CAER, This Conference.

(25) K. DEHGHAN, J.M. DUBOIS, G. LE CAER,C. TETE, to be submitted to J. Non Cryst. Sol.

(26) J.M. DUBOIS, G. LE CAER, Structure of Non Crystalline Materials II, Cambridge (1982) to be published.

(27) K. OSAMURA, K. SHIBUE, R. SUZUKI, Y. MURAKaMI, S, TAKaYAMA, J. Mat. Se. 16 (1981) 957.

(28) L. CSER, I. KOVACS, A. LOVAS, E. SVAB, G. ZSIGMONT, Nucl. Inst. Met. in press.

(29) P. LAMPARTER, W. SPERL, E. NOLD, E. RAINER-HARBACH, S. STEEB, Proc. 4 th Int. Conf. RQM, Sendà (1982)

(30) P. DUHAJ, F. HANTC, Phys. Phys. Stat. Sol. (a) 62, (1980) 719 ; K.P. MIZGALSKI, O.T. INAL, F.G. YOST, M.M. KARNOWSKY, J. Mat. Sc. 16 (1981) 3357.

(31) J. WELFRINGER, to be published.

(32) J. BLETRY, Z. Naturforsch. a 33 (1978) 327.

(33) J.M. DUBots, G. LE CAER, Mem. Sc. Revue Meta1. to be published S. AL BIJAT, R. IRALDI, J.M. DUBOIS, G. LE GAER, C. TETE, Proc. 4 th Int. Conf. RQM Sendai 1 (1982) 375 .

(34) N.NARITA, H. fUKUNAGA, J. YAMASAKI, K. HARA, Supp. Sc1. Rep. RITU A (1.980) 251

(35) R. HASEGAWA, RANJAN RAY. J. App1. Phys. 49-7 (1978) 4174.

(36) J.F. SADOC, J. de Phys. 41 (1980) C8-326.

(37) J.C. PHILIPS "Kinetic model of the glass Transition" to be published.

(38) J.C. PHILIPS, Phys. Stat. Sol. (b) 101 (1980) 473. 